OPEN ACCESS

Edited by:

Cesare Indiveri,

University of Calabria, Italy

Reviewed by:

Elena A. Ostrakhovitch,

Frontiers in Bioscience Research

Institute, United States

Elia Ranzato,

Università degli Studi del Piemonte

Orientale "Amedeo Avogadro," Italy

${ }^{*}$ Correspondence:

Bechan Sharma

sharmabi@yahoo.com

Specialty section:

This article was submitted to

Cellular Biochemistry,

a section of the journal

Frontiers in Chemistry

Received: 29 April 2017 Accepted: 11 September 2017 Published: 11 October 2017

Citation:

Singh N, Gupta VK, Kumar A and Sharma B (2017) Synergistic Effects of Heavy Metals and Pesticides in Living

Systems. Front. Chem. 5:70.

doi: 10.3389/fchem.2017.00070

\section{Synergistic Effects of Heavy Metals and Pesticides in Living Systems}

\author{
Nitika Singh, Vivek Kumar Gupta, Abhishek Kumar and Bechan Sharma* \\ Department of Biochemistry, Faculty of Science, University of Allahabad, Allahabad, India
}

There is a widespread repeated exposure of the population to the pesticides and heavy metals of occupational and environmental origin. Such population is forced to undergo continuous stress imposed by combined exposure of the heavy metals and different classes of the pesticides used in agricultural as well as health practices. The existing reports from several workers have indicated that heavy metals and pesticides in combination may lead more severe impact on the human health when compared to their individual effects. Such a combination of pesticides and heavy metals may also change or influence the detection of exposure. Several studies in past have shown the synergistic toxic effects of heavy metals and pesticides. Such evaluations have revealed the synergistic interactions of various heavy metals and pesticides in animals as well as humans. The aim of the present article is to provide a synthesis of existing knowledge on the synergistic effects of heavy metal and pesticides in living systems. The information included in this article may be useful for different environment protection agencies and policy makers to consider the combined effects of heavy metals and pesticides on humans while designing strategies toward environmental protection and safety regulations about human health.

Keywords: contamination, risk assessment, combined interaction, synergistic effect, heavy metal, pesticide

\section{INTRODUCTION}

Heavy metals are those inorganic elements which have five times the specific gravity of water (Fergusson, 1990). According to the Agency for Toxic Substances and Disease Registry (2007), arsenic, lead, cadmium (Cd), and mercury have serious health implications among the heavy metals (Csavina et al., 2012; Sharma et al., 2014; Gupta et al., 2015a). Among many heavy metals listed into the d-orbital elements of modern periodic table, arsenic, $\mathrm{Cd}$, mercury, and lead have got prime importance because of their patho-physiological significance as their bioaccumulation in living systems may cause severe damage to the vital organs, namely reproductive systems, nervous system, gastrointestinal tract, and mucous tissues (Sharma et al., 2014; Gupta et al., 2015b). Though the exact mechanism of their pathogenicity is not known but there are reports from various laboratories indicating that the exposure of these heavy metals or their excess accumulation in the body tissues may induce production of free radicals [reactive oxygen species (ROS) and reactive nitrogen species (RNS)] which lead to the production of oxidative stress (OS) (Figure 1; Flora et al., 2008; Sharma et al., 2014; Gupta et al., 2015a; Asmat et al., 2016).

Free radicals have been implicated into DNA damage, oxidation of thiol group(s) of proteins, and lipid peroxidation (LPO) (Figure 1; Valko et al., 2005) which is associated with the onset of 
various diseases. The $\mathrm{Cd}$ and lead are reported to be neurotoxic by inhibiting acetylcholinesterase (AChE) in blood (Gupta et al., 2015b,c) and brain (Gupta et al., 2015b,c), respectively. All heavy metals are toxic in sufficient quantities (Everson et al., 1988; Zukowska and Biziuk, 2008; Taghipour et al., 2014). Because of their presence in our environment and similarity with biochemical activity of some factors involved in the biochemical pathways, lead, mercury, $\mathrm{Cd}$, and arsenic mimics their functions and are of particular interest. Heavy metals produce toxicity by forming complexes with cellular compounds containing sulfur, oxygen, or nitrogen (Aguilera et al., 2017; Kumar et al., 2017; Trost and Tracy, 2017) on entering into our body through food, drinking water, and air. These complexes inactivate or modulate the critical enzyme systems or/protein structures leading to cellular dysfunction and necrosis (Sharma et al., 2014).

On the other hand, the widespread use of pesticides in public health and agricultural programs has caused severe environmental pollution and health hazards, including cases of severe, acute and chronic human poisoning (Satoh, 2006). Pesticides are substances (chemical compounds and naturally occurring phytochemicals) which are used to kill pests in agricultural as well as house hold practices (Damalas and Eleftherohorinos, 2011). They include compounds labeled as insecticides (organochlorines, organophosphates, carbamates, and pyrethroids), rodenticides (arsenic trioxide, barium carbonate and anticoagulants), herbicides (paraquat, diquat, and 2, 4-dichlorophenoxyacetic acid), fungicides (dithiocarbamates, and captan), and fumigants (ethylene dibromide, and methyl bromide (Randall et al., 2013).

According to the Food and Agricultural Organization of the United Sates pesticide are the substances or mixture of substances intended for preventing, destroying or controlling any pest, including vectors of disease, weeds, animals causing harm to the production of crops which may be administered to animals for the control of insects, arachnids or other pests in or on their bodies (Food Agriculture Organization of the United Nations, 2002).

Pesticides have been shown to induce the production of ROS which ultimately leads to the OS (Abdollahi et al., 2004; Sharma et al., 2015). Oxidative stress (OS) occurs when the production of ROS overrides the free radical quenching capacity/antioxidant capacity of the cells, which leads to the damage of cellular biomolecules (nucleic acids, lipids and proteins) involved in structural organization of the cell (Figure 1; Casida and Quistad, 2004; Agrawal and Sharma, 2010). An extensive survey on currently available literatures indicated that pesticide-induced OS has been considered as a possible mechanism of toxicity (Agrawal and Sharma, 2010). The pesticides are known to increase the rate of LPO by altering the activity of both the enzymatic (superoxide dismutase, catalase, and glutathione-S-transferase) and the levels of nonenzymatic (total glutathione, vitamin $\mathrm{C}$ and vitamin $\mathrm{E}$ ) antioxidative reserves of the cell and cause OS (Jaiswal et al., 2015, 2016; Figure 1). The impact of pesticide induced OS ranges from tissue injury and aging to the onset of various known/unknown diseases (Agrawal and Sharma, 2010; Agarwal et al., 2012; Chen et al., 2012). The combination exposure of chlorpyrifos (CPF) and $\mathrm{Cd}$ has been reported to decrease the mitochondrial potential and induced reactive oxygen species ( $\mathrm{Xu}$ et al., 2017b).

Some xenobiotics are recalcitrant in nature (Godheja et al., 2016) i.e., they are highly resistant to environmental degradation, such as synthetic organochlorines, natural organic compounds like polyaromatic hydrocarbons. The organochlorines contain carbon, chlorine and hydrogen; the carbon to halide bond being highly resistant to degradation. Therefore, the organochlorines are degraded very slowly and hence remain in the environment or/and inside the organisms after exposure for longer duration (Wandiga, 2001). Carbamates are derived from carbamic acid and used to kill insects/pests (Struger et al., 2016) in a similar fashion as organophosphates. It has been shown that carbofuran is highly neurotoxic and may modulate the functions of acetylcholinesterase (AChE) (Gupta et al., 2016). Organocarbamate pesticides are a class of insecticides which are not broad spectrum in insecticidal function as compared to organophosphates. Most of the carbamates are extremely toxic to hymenoptera (Brunner et al., 2001). It is thirdlargest order of insects which contains over 150,000 species of arthropods. It comprises the sawflies, wasps, bees, and ants hence the precautions must be taken to avoid exposure to these insects. The pesticide (organocarbamate) exposure to the humans may occur through the inhalation of contaminated air, dermal contact to soils, air and water, drinking water and eating contaminated food (Agrawal and Sharma, 2010). Organophosphates are also a group of wide spectrum pesticides which are reported to be highly neurotoxic and causes several diseases to humans (Agrawal and Sharma, 2010; Gupta and Sharma, 2016). The present article illustrates an updated account of the synergistic effects of heavy metals and the pesticides into different organs of the animals and humans. The manuscript provides a synthesis of existing knowledge on the synergistic effect of heavy metals and pesticides in living system.

\section{ABSORPTION, DISTRIBUTION AND EXCRETION OF HEAVY METALS AND PESTICIDES EXPOSURE}

It has been reported that heavy metals and pesticides mainly enter into the human/animal body through ingestion, such as food materials (Satarug et al., 2003), inhalation and dermal contact, such as emissions of waste material in the form of smoke, dust particle, fume of chemicals from several industrial activities, such as mining, and manufacturing of batteries (Agency for Toxic Substances and Disease Registry, 2007). Other sources of heavy metals a $d$ pesticides exposure to human are agricultural practices, working and smoking in pesticide, heavy metal infested environments, and household practices are the major contributor (International Agency for Research on Cancer, 1993; Paschal et al., 2000). The route of absorption, distribution and excretion related to the exposure of heavy metals and pesticides have been summarized in Figure 2. 


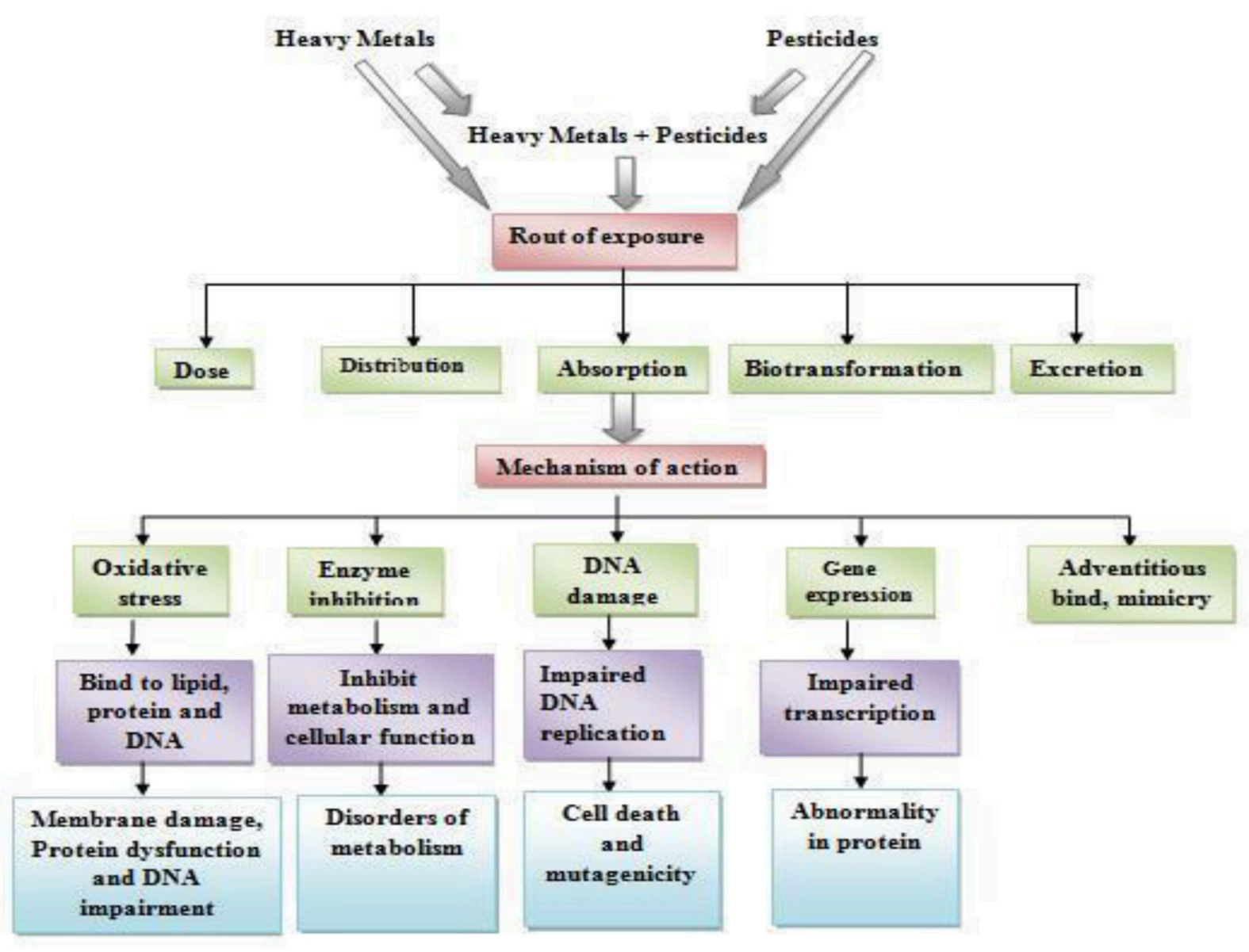

FIGURE 1 | Route of exposure and mechanisms of action of heavy metals and pesticides.

\section{SYNERGISTIC EFFECT OF HEAVY METALS AND PESTICIDES}

The living organisms in nature are frequently exposed to a mixture of xenobiotics (heavy metals, pesticides, and toxic gases etc.) simultaneously. The xenobiotic substances have been reported to cause toxicity in animals as well as in key organs of the humans also (Omiecinski et al., 2011; Oesch et al., 2014). Therefore, the combined interactions between xenobiotic substances as well as xenobiotic and animal systems are very important (Oesch et al., 2014). Combined exposure to Cd and ethanol has been shown to produce increased level of norepinephrine in hypothalamus and mid brain of rats in comparison to the rats exposed to only Cd (Flora and Tandon, 1987). The combined effect of heavy metals and pesticides has been listed in Table $\mathbf{1 .}$

According to Groten et al. (1997) the exposure of rats to arsenic-lead combinations may produce significant changes in the central monoaminogenic system. Whereas, these alterations were not present when the animals were treated with the same doses of each heavy metals (arsenic and lead) in separate (Mejia et al., 1997). The immunotoxic properties have also been observed due to the combined oral exposures exposure of pesticides and heavy metals in rats (Institóris et al., 1999, 2001a). The interactions occur in both combinations, dimethoatecadmium (DM-Cd) (Institóris et al., 2002) and dimethoate-lead $(\mathrm{DM}-\mathrm{Pb})$ may result into the body weight gain and relative weight gain to liver also (Institóris et al., 1999). The dimethoatelead $(\mathrm{DM}-\mathrm{Pb})$ combination also affected the relative thymus weight and the mean corpuscular volume $(\mathrm{MCV})$ value. These findings showed that the immunotoxic effects of the investigated materials, including their detectability and health consequences can be modified in case of combined exposure (Institóris et al., 1999).

According to the Institóris et al. (2001c), the effects of exposures to cadmium ( $\mathrm{CdCl} 2)$-propoxur $(\mathrm{Pr})$ as well as rats treated subacutely with dimethoate, $\mathrm{As}^{3+}$ and $\mathrm{Hg}^{2+}$, has been found to be toxic on the levels of body weight gain, relative organ weights, hematological (RBC, WBC, Ht, MCV, cell content of the femoral bone marrow), immune function, delayed hypersensitivity reaction and neurotoxicity in male Wistar rats. However, a significant interaction between $\mathrm{Cd}$ and $\mathrm{Pr}$ has also been reported (Institóris et al., 2001c, 2002). The main issue raised by these studies is whether the Lowest Observed Effect 


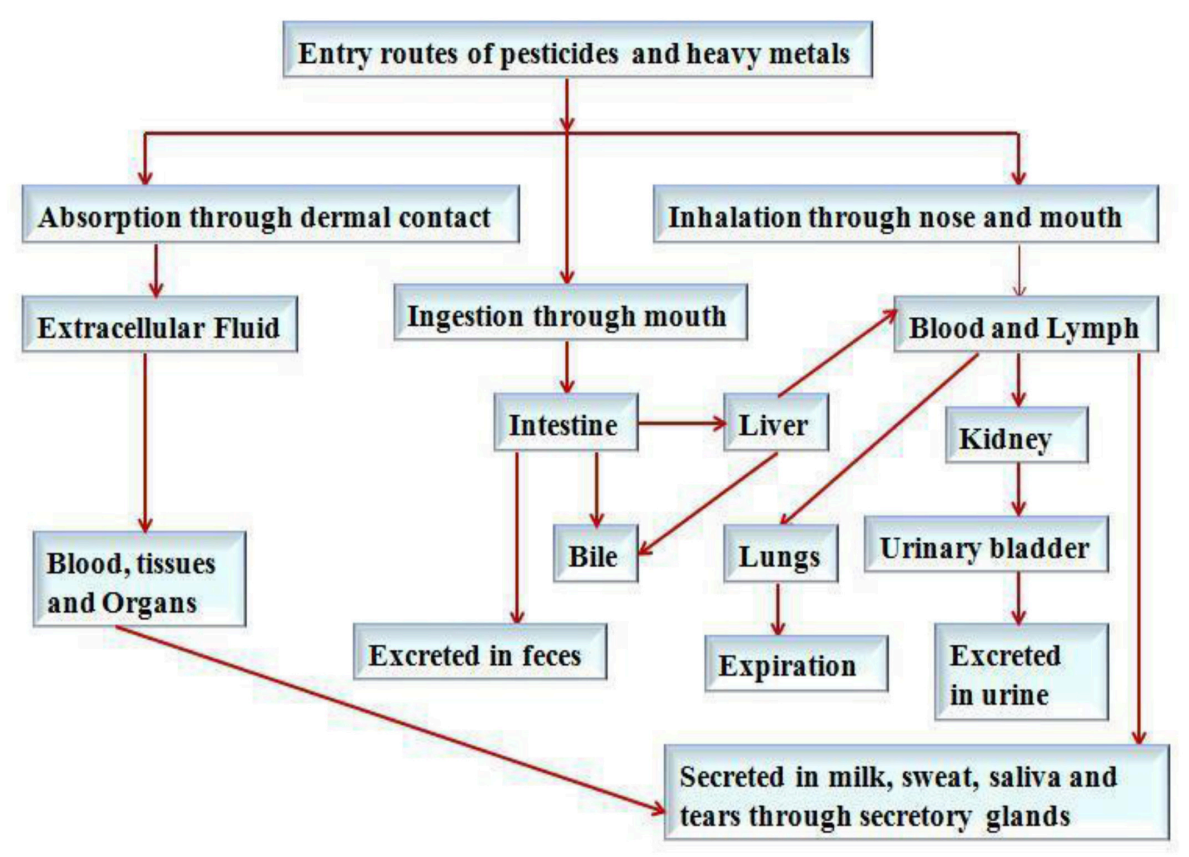

FIGURE 2 | Routes of absorption, distribution and excretion related to the exposure of heavy metals and pesticides in humans.

TABLE 1 | Synergistic effects of heavy metals and pesticides.

\begin{tabular}{|c|c|c|c|}
\hline S. No. & Synergistic exposure & References & Effect \\
\hline 2 & Cadmium and Dimethoate & Institóris et al., 1999, 2001b & Affects relative body weight gain and relative liver weight \\
\hline 4 & Cadmium and Propoxur & Institóris et al., 2002 & Alter immuno and neurotoxicological function. \\
\hline 5 & Cadmium and Diazi on & Creasy, 2001; Adamkovicova et al., 2014 & $\begin{array}{l}\text { Notable loss of spermatogenic element, disorganization and seminiferous } \\
\text { epithelium and lacking maturation of germs cells }\end{array}$ \\
\hline 6 & Mercury and Dimethoate & Institóris et al., 2001b & $\begin{array}{l}\text { Alteration in body weight gain, relative liver and kidney weights and in PFC } \\
\text { (Igm-plaqueforming cell) }\end{array}$ \\
\hline 7 & Arsenic and Dimethoate & Institóris et al., 2001b & Change in relative liver weight MCV and PFC content of spleen \\
\hline 8 & Nickel and Chlorpyrifos & Staal et al., 2007, 2008 & Change in molecular fingerprints \\
\hline 9 & Arsenic and Lead & Mejia et al., 1997 & Alreration in central monoaminogenic system Neurotoxicity and cytotoxicity \\
\hline 10 & Mercury and Lead & Mejia et al., 1997 & \\
\hline
\end{tabular}

Level (LOEL) dose of heavy metals may modulate the toxic effects of Non-Observable Effect Level (NOEL) doses of pesticides (Institóris et al., 2002). Due to having common targets and mechanisms of action, the interaction of Pr and $\mathrm{Cd}$ is more likely kinetic. The combined sub-acute exposure of propoxur (carbamate pesticide) and Cd (heavy metal) in rats showed stronger effect than the separate high dose component of the corresponding combinations (Institóris et al., 2002).

The combined exposure of dimethoate (DM) with $\mathrm{HgCl} 2$ $(\mathrm{Hg})$, and $\mathrm{NaAsO} 2$ (As) has been reported to acquire some abnormality like weight gain of organs (such as weights of brain, thymus, heart, lung, kidneys, adrenals, spleen, testicles), cell count of popliteal lymph node, white blood cell and red blood cells, mean cell volume (MCV) of RBCs, cell content of the femoral bone marrow, IgM-plaque forming cell (PFC) content of the spleen, and delayed hypersensitivity reaction in male rats (Institóris et al., 2001b). The dimethoate-mercury (DM$\mathrm{Hg}$ ) combination significantly may cause alterations in the body weight gain, relative liver and kidney weights, and in the plaque forming cell response (Institóris et al., 2001b). However, when dimethoate (DM) as combined with arsenic (As), the significant changes in relative liver weight, value of MCV, and IgM-PFC content of the spleen has been shown (Institóris et al., 2001b).

Chlorpyrifos (CPF) and Nickel (Ni) has been shown to elicit distinct molecular fingerprints and giving rise to a complex transcriptional profile in mixture of both (Dondero et al., 2011; Boatti et al., 2012). Very little studies are known about the dose response relationships between exposures to mixture of 
xenobiotics on the levels of changes in gene expression. Some studies have reported that the transcriptional patterns found in mixture-exposed samples were largely inherited from the single chemicals (Staal et al., 2007, 2008).

Administration of diazinon and $\mathrm{Cd}$ has been reported to cause significant loss of spermatogenic elements (Adamkovicova et al., 2014). A progressive damage in epithelial cells were represented by seminiferous tubules devoid of germ cells and lined by Sertoli cells only (Creasy, 2001) of most seminiferous tubules. The weight of epididymis, testes, and other accessory sex organs, are primary indicators of a possible alteration in androgen status (Biswas et al., 2002; Adamkovicova et al., 2014).

The combined exposure of $\mathrm{Cd}$ and diazinon on testis and epididymis has been shown some tubules developing sperm exhibited degeneration and disorganization of seminiferous epithelium, lack in the characteristic maturation of germ cells, and disruption of tight junctions which led to hemorrhaging and edema like conditions in testes (Adamkovicova et al., 2014). Significantly increase in the weight of testis after combined exposure of $\mathrm{Cd}$ and diazinon may increase interstitial fluid and damage to the vascular endothelium (Lanning et al., 2002). Furthermore, the dilatation and congestion of the interstitial blood vessels together with necrotizing vasculitis were identified (Fouad et al., 2009). However, the structural perturbations observed in testicular tissue were less expressive than after exposure to diazinon or $\mathrm{Cd}$. The synergistic effect of diazinon and $\mathrm{Cd}$ was different from estimates in comparison to the addition of individual xenobiotic (diazinon and $\mathrm{Cd}$ ) responses (Feron and Groten, 2002).

Similarly, the co-exposure of Cd with nickel (Ni) did not have a synergistic effect on testicular tissues. Combined administration of $\mathrm{Cd}$ with nickel may produce fewer pathological alterations than that of $\mathrm{Cd}$ alone (İşcan et al., 2002). The synergistic effect of lead $(\mathrm{Pb})$ and mercury $(\mathrm{Hg})$ are extremely neurotoxic and has been reported to be much worse than the single one (Wildemann et al., 2015). The amount of mercury as well as lead sufficient to kill $1 \%$ of rats when administered individually, when administered in the combined may kill 100\% of rats tested (http:// amalgam.org/education/scientific-evidenceresearch/synergisticeffects-of-mercury-other-toxic-exposures/) (Sheets and Sheet, 2018).

In a recent study, the amount of $\mathrm{Cd}$ and $\mathrm{DM}$ were reported that they are not enough to achieve the toxicological target individually by using cellular pathways. Cd and DM exhibited an additive type of toxicity (Rehman et al., 2017). In animals, IgM antibodies producing PFCs are markedly reduced in number by $\mathrm{DM}$ and $\mathrm{Cd}$, as well as by their combinations. Whereas, the oral administration of some pesticides, such as carbaryl, malathion, endosulfan, CPF, quinalphos, and alphamethrin has been reported to suppress the humoral immune response (Wiltrout et al., 1978).

The Cd and CPF induced the protein and LPO, disturbed the total antioxidant capability of cell or organism, and altered ultra-structure of mitochondria in the brain by the oxidative damage. CPF and Cd have been found to lower the potential of mitochondria and generate ROS in SH-SY5Y cells. It has been found that the mixture of $\mathrm{CPF}$ and $\mathrm{Cd}$ did not display higher toxicity than the sum of the individual treatments. Therefore, it was concluded that they could have a potential antagonistic interaction on the OS induction (Xu et al., 2017b). However, the exact interactions between $\mathrm{CPF}$ and $\mathrm{Cd}$ are not well-known and needs to be further more investigation regarding their mechanism. Although previous investigation to occurrence and interaction of $\mathrm{Cd}$ and $\mathrm{CPF}$ simultaneous in environmental medium including food chains show synergistic potential of Toxicity remain elusive thus far. $\mathrm{Cd}^{2+}$ and $\mathrm{CPF}$ was found to be hepatoxic. By using thin-layer chromatography (TLC) and Nuclear magnetic resonance (NMR) spectroscopy techniques, a novel interaction mechanism between $\mathrm{Cd}^{2+}$ and $\mathrm{CPF}$ has been reported. In this interaction bonding between $\mathrm{Cd}^{2+}$ and nitrogen atom in the pyridine ring of $\mathrm{CPF}$, or the chelation between one $\mathrm{Cd}^{2+}$ and two CPF molecules (He et al., 2015). The complex of Cd-CPF showed distinct biological responses and toxicological fates which were different from its parental components. In this study, the joint hepatoxicity of Cd ion and CPF was demonstrated (He et al., 2015). The cause of this hepatoxicity is the formation of Cd-CPF complex which further facilitate the intracellular transport which has been again, reported to be associated with the OS.

The toxicological responses of single substances may be modified by interactions between heavy metals and pesticides which may change the detection limits of their exposure. If the change in detection limits of heavy metals and pesticides occur, it can lead to false-positive and/or false-negative results (Rehman et al., 2017). Further it is necessary to characterize the nature of toxicity on organ system in animals as well as in humans due to the co-exposure of heavy metals and pesticides (Xu et al., 2017a).

In plant system, the synergistic toxicity of heavy metals and pesticides has not been reported well. Very few workers have described the toxicity of heavy metal along with pesticides. (Chen et al., 2004), investigated the combined pollution of 2,4dichlorophenol (2,4-DCP) along with $\mathrm{Cu}$ and $\mathrm{Zn}$. The treatment of 2,4-DCP had limited effect on the dissolution of $\mathrm{Cu}$ and $\mathrm{Zn}$ in the soil without plant root growth. But the metal species might be changed due to the addition of organic pollutant. Planting with rye grass for 1 month, greatly increased both water soluble $\mathrm{Cu}$ and $\mathrm{Zn}$. The increase of water soluble $\mathrm{Cu}$ and $\mathrm{Zn}$ in the presence of 2,4-DCP was much more than that in the absence of 2,4-DCP, which suggested more attention should be paid to the behavior of heavy metals under combined pollution of organic pollutants, such as pesticides in the planted soil (Chen et al., 2004). The combined effect of more than heavy metal and pesticide in plants have been reported by several workers (Rai et al., 2009; Ong et al., 2013) but in case of combined effect of heavy metal and pesticide in plants sufficient data are not available.

\section{MECHANISM OF INTERACTIONS BETWEEN HEAVY METALS AND PESTICIDES}

According to FAO and WHO (2009), the chemical substances to which humans are exposed in the environment have almost infinite number of simple, binary, tertiary and quaternary 
combinations. The direct experimentation has been found to be unable to resolve the risk assessment issue. According to the recent reports, the research focused on understanding basic science of combination toxicology there are four types of combined effect or interaction being reported which are given below:

1. Dose addition: In such type of interactions the toxicity produced through the same mode of action. If there is exposure to a mixture that contains a large number of substances that have the same mechanism of action, may be produced even though the exposures of each substance are too low to elicit a response. According to the dose addition is the basis for recent considerations of pesticides that share the same mode of action.

2. Response addition: In this interaction both the substances have different mechanisms of action and individual substance exposure has to be sufficient to cause a response without involvement of other substance. For substance, an active dose of a combination of a neurotoxin and a hepatotoxin produces neurotoxicity and hepatotoxicity and same results were seen when each were given separately. Such interactions are not relevant to the exposures of multiple substances.

3. Synergism: Synergism typically occurs when at least one of the components is present to affect the biological system. It occurs when the effect of combination is greater than predicted by the summed activity of each component individually at the same level of exposure that occurs in the mixture. Toxicokinetic interactions occur only when one substance change the metabolism of the other potentially more toxic substance to enhance the internal dose or systemic exposure of the active form of the toxic component (parent compound or metabolite). Such interactions may enhance the activity of the toxic substance which enhances the pesticide activity of the formulation in the target organism.

4. Antagonism: In antagonism both the compounds are essential and present at active concentrations. The toxicokinetic/toxicodynamic interactions may result into antagonism. These interactions may decrease the toxicity of the active compound(s). In antagonism two substances occur in which one substance is with low efficacy compete with second substance with high efficacy also known as partial agonist and full agonist, respectively.

For the evaluation of potential of mixture toxicity in reference to the risk assessment of environmental pollutants and its adverse effect on health, a large number of data is required. It is very difficult to decipher the interaction between compounds, because of limited techniques (Chen et al., 2013). There is no any mechanism of interaction has been reported between heavy metals and pesticides. The pesticide and heavy metals may affect the toxicity of each other, which could enhances or decreases the effect of resulting toxic effect and might be responsible for the cumulative effect of both the xenobiotics. The toxicity mechanism of heavy metals and pesticides has been well reported in individual doses separately. However, the synergistic toxicity mechanism of xonobiotics has not been reported clearly. Till now there is no any study found that reported as how heavy metals and pesticides influence or affect the toxicity of each other. Therefore, more study should be focused in this area.

An insecticides and heavy metals contamination show significant health risk to humans under the biological and environmental settings poses (Chen et al., 2013; He et al., 2015). Genotoxic and carcinogenic substances may show their non-linear dose-response relationships. The dose-response assessment should be based on the available dose-response data. The dose metric could be a biomarker for the generation of cancer, and could be validated in relation to the dose. The individual studies of heavy metals and pesticides biotransformation has been studied by many workers. However, there are not enough work has been done in the field of biotransformation of heavy metals and pesticides with respect to the combined study as well as their mechanism by which they affect the toxicity to each other.

\section{ROLE OF ENDOGENOUS ANTIOXIDANT SYSTEM IN REDUCING TOXICITY}

Endogenous antioxidant system includes both enzymatic and non-enzymatic antioxidants. Some specific antioxidant enzymes, such as Glutathione-S-transferases (GST), glutathione peroxidase $(\mathrm{GPx})$, superoxide dismutase (SOD), catalase, peroxidase and GSH are known to be involved in cellular redox reactions. The endogenous antioxidants (Catalase, GPx, and SOD) play important roles in defense mechanism against OS caused by heavy metals, pesticides as well as their combinations. Lead induced toxicity is mediated by enhancing the production of free radical compounds, such as hydroxyl radical $(\bullet \mathrm{OH})$, superoxide radical $\left(\mathrm{O}^{-2}\right)$, nitric oxide $(\bullet \mathrm{NO})$ and peroxynitrite $\left(\mathrm{ONOO}^{-}\right)$. The major mechanism by which SOD and CAT reduce the OS caused by xenobiotics especially heavy metals, pesticides and their combinations involves decrease in the free radicals concentration by converting the ROS and RNS into nonreactive or less reactive form. The SOD, a metalloenzyme, is responsible for catalyzing the dismutation of the superoxide radical to hydrogen peroxide as a defense mechanism against oxygen toxicity (Simurda et al., 1988). GPx is also involved in this process and eliminate the free radical species by inactivating the hydrogen and lipid peroxides (Flora et al., 2008). The inhibition of phospholipid peroxidation by glutathione peroxidase (GPx), protects membranes from the oxidative damage. It also acts as a H2O2 metabolizing enzyme (Williams et al., 1992; Kwatia et al., 2000). Glutathione-S-transferases (GST) functions to neutralize free radicals causing potential membrane damage via linked catalysis of glutathione (GSH) reduction with detoxification reactions involving thiol-conjugation to xenobiotics (Yan et al., 2008). Catalase, an enzyme responsible for $\mathrm{H} 2 \mathrm{O} 2$ metabolism, is functionally replaced by peroxiredoxin ( Prx) and GPx in some organism (Sayed et al., 2006).

\section{CONCLUSION}

The information retrieved from the extensive literature survey indicates that the combinations of pesticides with pesticides, pesticide with heavy metal, and heavy metal to heavy metal 
acts synergistically and exhibit more toxicity than a single molecule alone. The studies relating heavy metals (Cd and $\mathrm{Pb}$ ) are also reported to be displaying accelerated toxicological, hematological and immunological indices. In case of humans, the combined exposure of these xenobiotic substances acts in two different ways: firstly, the toxic hazard of a single component could be modified in combined exposures, which can lead to unexpected adverse health consequences. Studies demonstrated that a variety of chemicals may contribute to behavioral disabilities, developmental, and learning impairment. Humans are generally exposed by not only the oral route but also by dermal contact, inhalation, as well as ingestion. Secondly, the delectability of the toxic effects (including immunotoxic) of a single compound can be changed by the interactions with one or more with other heavy metal or other xenobiotics. Thus, the synergistic interactions between pesticides and heavy metals may lead to several health consequences which needed further investigations.

\section{REFERENCES}

Abdollahi, M., Ranjbar, A., Shadnia, S., Nikfar, S., and Rezaie, A. (2004). Pesticides and oxidative stress: a review. Med. Sci. Monit. 10, 141-147.

Adamkovicova, M., Toman, R., Cabaj, M., Massanyi, P., Martiniakova, M., Omelka, O., et al. (2014). Effects of subchronic exposure to cadmium and diazinon on testis and epididymis in rats. Sci. World J. 2014:632581. doi: 10.1155/2014/632581

Agarwal, A., Aponte-Mellado, A., Premkumar, B. J., Shaman, A., and Gupta, S. (2012). The effects of oxidative stress on female production: a review. Reprod. Biol. Endocrinol. 10:49. doi: 10.1186/1477-7827-10-49

Agency for Toxic Substances and Disease Registry (2007). Draft Toxicological Profile for Cadmium. Atlanta, GA: ATSDR.

Agrawal, A., and Sharma, B. (2010). Pesticides induced oxidative stress in mammalian systems: review article. Int. J. Biol. Med. Res. 1, 90-104.

Aguilera, G., Colín-González, A. L., Rangel-López, E., Chavarría, A., and Santamaría, A. (2017). Redox signaling, neuroinflammation, and neurodegeneration. Antioxid. Redox Signal. doi: 10.1089/ars.2017.7099. [Epub ahead of print].

Asmat, U., Abad, K., and Ismail, K. (2016). Diabetes mellitus and oxidative stress-A concise review. Saudi Pharm J. 24, 547-553. doi: 10.1016/j.jsps.2015.03.013

Biswas, N. M., Gupta, R. S., Chattopadhyay, A., Choudhury, G. R., and Sarkar, M. (2002). Effect of atenolol on cadmium-induced testicular toxicity in male rats. Reprod. Toxicol. 15, 699-704. doi: 10.1016/S0890-6238(01)00184-8

Boatti, L., Robotti, E., Marengo, E., Viarengo, A., and Marsano, F. (2012). Effects of nickel, chlorpyrifos and their mixture on the dictyostelium discoideum proteome. Int. J. Mol. Sci. 13, 15679-15705. doi: 10.3390/ijms1312 15679

Brunner, J. F., Dunley, J. E., Doe, M. D., and Beers, E. H. (2001). Effect of pesticides on Colpoclypeus florus (Hymenoptera: Eulophidae) and Trichogramma platneri (Hymenoptera: Trichogrammatidae), parasitoids of leaf rollers in Washington. J. Econ. Entomol. 94, 1075-1084. doi: 10.1603/0022-0493-94.5.1075

Casida, J. E., and Quistad, G. B. (2004). Organophosphate toxicity: safety aspects of non-acetylcholinesterase secondary targets. Chem Res Tox. 17, 983-998. doi: 10.1021/tx0499259

Chen, L., Qu, G., Sun, X., Zhang, S., Wang, L., Sang, N., et al. (2013). Characterization of the interaction between cadmium and chlorpyrifos with integrative techniques in incurring synergistic hepatoxicity. PLoS ONE 8:e59553. doi: 10.1371/journal.pone.0059553

Chen, X., Guo, C., and Kong, J. (2012). Oxidative stress in neurodegenerative diseases. Neural Regen. Res. 7, 376-385. doi: 10.3969/j.issn.1673-5374.2012.05.009

\section{AUTHOR CONTRIBUTIONS}

NS, VKG, and AK wrote the review article, prepared and assembled the Figures and Table; BS critically organized and revised the manuscript by incorporating significant reports.

\section{FUNDING}

The work was supported by University Grant Commission New Delhi at University of Allahabad, Allahabad.

\section{ACKNOWLEDGMENTS}

NS, VKG, and AK gratefully thank to the University Grant Commission, New Delhi, for providing financial support in the form of a Research Fellowship.

Chen, Y. X., Lin, Q., He, Y. F., and Tian, G. M. (2004). Behavior of Cu and Zn under combined pollution of 2,4-dichlorophenol in the planted soil. Plant Soil 261, 127-134. doi: 10.1023/B:PLSO.0000035581.92021.f2

Creasy, D. M. (2001). Pathogenesis of male reproductive toxicity. Toxicol. Pathol. 29, 64-76. doi: 10.1080/019262301301418865

Csavina, J., Field, J., Taylor, M. P., Gao, S., Landázuri, A., Betterton, E. A., et al. (2012). A review on the importance of metals and metalloids in atmospheric dust and aerosol from mining operations. Sci. Total Environ. 433C, 58-73. doi: 10.1016/j.scitotenv.2012.06.013

Damalas, C. A., and Eleftherohorinos, I. G. (2011). Pesticide exposure, safety issues, and risk assessment indicators. Int. J. Environ. Res. Public Health. 8, 1402-1419. doi: 10.3390/ijerph8051402

Sheets, D. F., and Sheet, D. M. F. (2018). Synergistic Effects of Mercury and Other Toxic Exposures. Available online at: http://amalgam.org/education/scientificevidenceresearch/synergistic-effects-of-mercury-other-toxic-exposures/

Dondero, F., Banni, M., Negri, A., Boatti, L., Dagnino, A., and Viarengo, A. (2011). Interactions of a pesticide/heavy metal mixture in marine bivalves: a transcriptomic assessment. BMC Genomics 12:195. doi: 10.1186/1471-2164-12-195

Everson, G. W., Normann, S. A., and Casey, J. P. (1988). Chemistry set chemicals: an evaluation of their toxic potential. Vet. Hum. Toxicol. 30, 589-592.

FAO and WHO (2009). Principles and Methods for the Risk Assessment of Chemicals in Food Environmental Health Criteria 240, Chapter no.-7 Risk Assessment. ISBN: 9789241572408.

Fergusson, J. E. (1990). The Heavy Elements: Chemistry, Environmental Impact and Health Effects. Oxford: Pergamon Press.

Feron, V. J., and Groten, J. P. (2002). Toxicological evaluation of chemical mixtures. Food Chem. Toxicol. 40, 825-883. doi: 10.1016/S0278-6915(02)00021-2

Flora, S. J. S., Chouha, S., Kannan, G. M., Mittal, M., and Swarnkar, H. (2008). Combined administration of taurine and monoisoamyl DMSA protects arsenic induced oxidative injury in rats. Oxid. Med. Cell. Longev. 1, 39-45. doi: 10.4161/oxim.1.1.6481

Flora, S. J. S., and Tandon, S. K. (1987). Effect of combined exposure to cadmium and ethanol on regional brain biogenic amine levels in the rat. Biochem. Int. 15, $863-871$.

Food and Agriculture Organization of the United Nations (2002). International Code of Conduct on the Distribution and Use of Pesticides. Rome: Food and Agriculture Organization of the United Nations (FAOUN) (Accessed October $25,2007)$.

Fouad, A. A., Qureshi, H. A., Al-Sultan, A. I., Yacoubi, M. T., and Ali, A. A. (2009). Protective effect of hemin against cadmium-induced 
testicular damage in rats. Toxicology 257, 153-160. doi: 10.1016/j.tox.2008. 12.022

Godheja, J., Shekhar, S. K., Siddiqui, S. A., and Modi, D. R. (2016). Xenobiotic compounds present in soil and water: a review on remediation strategies. J. Environ. Anal. Toxicol. 6:392. doi: 10.4172/2161-0525.1000392

Groten, J. P., Schonen, E. D., Bladeren, P. J., Kuper, C. F., Zorge, J. A., and Feron, V. J. (1997). Subacue toxicity of a mixture of nine chemicals in rats: detecting interactive effects with a fractionated two-level factorial design. Fundam. Appl. Toxicol. 36, 15-29. doi: 10.1006/faat.1996.2281

Gupta, V. K., Singh, S., Agrawal, A., Siddiqi, N. J., and Sharma, B. (2015a). Phytochemicals mediated remediation of neurotoxicity induced by heavy metals. Biochem. Res. Int. 2015:534769. doi: 10.1155/2015/534769

Gupta, V. K., Kumar, A., Siddiqi, N. J., and Sharma, B. (2015b). Rat brain acetyl cholinesterase as a biomarker of cadmium induced neurotoxicity. Open Access J. Tox. 1:555553.

Gupta, V. K., Pal, R., Siddiqi, N. J., and Sharma, B. (2015c). Acetylcholinesterase from human erythrocytes as a surrogate biomarker of lead induced neurotoxicity. Enzyme Res. 2015:370705. doi: 10.1155/2015/370705

Gupta, V. K., Pathak, A., Siddiqi, N. J., and Sharma, B. (2016). Carbofuran modulating functions of acetylcholinesterase from rat brain in vitro. Adv. Biol. 2016:3760967. doi: 10.1155/2016/3760967

Gupta, V. K., and Sharma, B. (2016). Alleviation of acute poisoning of organophosphates in humans. Anat. Physiol. Biochem. Int. J. 1:555558.

He, W., Guo, W., Qian, Y., Zhang, S., Ren, D., and Liu, S. (2015). Synergistic hepatotoxicity by cadmium and chlorpyrifos: disordered hepatic lipid homeostasis. Mol. Med. Rep. 12, 303-308. doi: 10.3892/mmr.2015.3381

International Agency for Research on Cancer (1993). Monographs-Cadmium. Lyon: IARC.

Institóris, L., Papp, A., Siroki, O., Banerjee, B. D., and Dési, I. (2002). Immunoand neurotoxicological investigation of combined subacute exposure with the carbamate pesticide propoxur and cadmium in rats. Toxicology 178, 161-173. doi: 10.1016/S0300-483X(02)00239-1

Institóris, L., Siroki, O., and Dési, I., Ũndeger, Ũ. (1999). Immunotoxicological examination of repeated dose combined exposure by dimethoate and two heavy metals in rats. Hum. Exp. Toxicol. 18, 88-94. doi: 10.1177/096032719901800205

Institóris, L., Siroki, O., Ũndeger, Ũ., Basaran, N., Banerjee, B. D., and Dési, I. (2001c). Detection of the effects of repeated dose combined propoxur and heavy metal exposure by measurement of certain toxicological, haematological and immune function parameters in rats. Toxicology 163, 185-193. doi: 10.1016/S0300-483X(01)00381-X

Institóris, L., Siroki, O., Ũndeger, Ũ., Basaran, N., and Dési, I. (2001a). Immunotoxicological investigation of subacute combined exposure by permethrin and the heavy metals arsenic(III) and mercury(II) in rats. Int. J. Immunopharmacol. 1, 925-933. doi: 10.1016/S1567-5769(01)00029-7

Institóris, L., Siroki, O., Ũndeger, Ũ., Basaran, N., and Dési, I. (2001b). Immunotoxicological investigations on rats treated subacutely with dimethoate, $\mathrm{As}^{3+}$ and $\mathrm{Hg}^{2+}$ in combination. Hum. Exp. Toxicol. 20, 329-336. doi: 10.1191/096032701680350569

İşcan, M., Ada, A. O., Çoban, T., Kapucuoğlu, N., Aydin, A., and Işimer, A. (2002). Combined effects of cadmium and nickel on testicular xenobiotic $\mathrm{m}$ tabolizing enzymes in rats. Biol. Trace Element. Res. 89, 177-190. doi: 10.1385/BTER:89:2:177

Jaiswal, S. K., Gupta, V. K., Siddiqi, N. J., Pandey, R. S., and Sharma, B. (2015). Hepatoprotective effect of citrus limon fruit extract against carbofuran induced toxicity in wistar rats. Chin. J. Biol. 2015:686071. doi: 10.1155/2015/686071

Jaiswal, S. K., Sharma, A., Gupta, V. K., Singh, R. K., and Sharma, B. (2016). Curcumin mediated attenuation of carbofuran induced oxidative stress in rat brain. Biochem. Res. Int. 2016:7637931. doi: 10.1155/2016/7637931

Kumar, A., Yegla, B., and Foster, T. C. (2017). Redox signaling in neurotransmission and cognition during aging. Antioxid. Redox Signal. doi: 10.1089/ars.2017.7111. [Epub ahead of print].

Kwatia, M. A., Botkin, D. J., and Williams, D. L. (2000). Molecular and enzymatic characterization of Schistosoma mansoni thioredoxin peroxidase. J. Parasitol. 86, 908-915. doi: 10.1645/0022-3395(2000)086[0908:MAECOS]2.0.CO;2

Lanning, L. L., Creasy, D. M., and Chapin, R. E. (2002). Recommended approaches for the evaluation of testicular and epididymal toxicity. Toxicol. Pathol. 30, 507-520. doi: 10.1080/019262302 13168
Mejia, J. J., Diaz-Barriga, F., Calderson, J., and Rios, C., JimenezCapdeville, M. F. (1997). Effects of lead-arsenic combined exposure on central monoaminergic systems. Neurotoxicol. Teratol. 19, 489-497. doi: 10.1016/S0892-0362(97)00066-4

Oesch, F., Fabia, E., Guth, K., and Landsiedel, R. (2014). Xenobiotic-metabolizing enzymes in the skin of rat, mouse, pig, guinea pig, man, and in human skin models. Arch. Toxicol. 88, 2135-2190. doi: 10.1007/s00204-014-1382-8

Omiecinski, C. J., Vanden Heuvel, J. P., Perdew, G. H., and Peters, J. M. (2011). Xenobiotic metabolism, disposition, and regulation by receptors: from biochemical phenomenon to predictors of major toxicities. Toxicol. Sci. 120, S49-S75. doi: 10.1093/toxsci/kfq338

Ong, G. H., Yap, C. K., Maziahm, M., and Tans, S. G. (2013). Synergistic and antagonistic effects of zinc bioaccumulation with lead and antioxidant activities in centella asiatica. Sains Malays. 42, 1549-1555.

Paschal, D. C., Burt, V., Caudill, S. P., Gunter, E. W., Pirkle, J. L., Sampson, E. J., et al. (2000). Exposure of the U.S. population aged 6 years and older to cadmium: 1988-1994. Arch. Environ. Contam. Toxicol. 38, 377-383. doi: $10.1007 / \mathrm{s} 002449910050$

Rai, D. K., Rai, P. K., Gupta, A., Watal, G., and Sharma, B. (2009). Cartap and carbofuran induced alterations in serum lipid profile of wistar rats. Ind. J. Clin. Biochem. 24, 198-201. doi: 10.1007/s12291-009-0036-8

Randall, C., Hock, W., Crow, C., Hudak-Wise, E., and Kasai, J. (2013). National Pesticide Applicator Certification Core Manual (2013). Washington, DC: National Association of State Departments of Agriculture Research Foundation.

Rehman, H., Aziz, A. T., Saggu, S., VanWert, A. L., Zidan, N., and Saggu, S. (2017). Additive toxic effect of deltamethrin and cadmium on hepatic, hematological, and immunological parameters in mice. Toxicol. Ind. Health 33, 495-502. doi: $10.1177 / 0748233716684710$

Satarug, S., Baker, J. R., Urbenjapol, S., Haswell-Elkins, M., Reilly, P. E., Williams, D. J., et al. (2003). A global perspective on cadmium pollution and toxicity in non-occupationally exposed population. Toxicol. Lett. 137, 65-83. doi: 10.1016/S0378-4274(02)00381-8

Satoh, T. (2006). "Global epidemiology of organophosphate and carbamate poisonings," in Toxicology of Organophosphate and Carbamate Compounds. 1st Edn., ed R. C. Gupta (Burlington, MA: Elsevier Academic Press).

Sayed, A. A., Cook, S. K., and Williams, D. L. (2006). Redox balance mechanisms in Schistosoma mansoni rely on peroxiredoxins and albumin and implicate peroxiredoxins as novel drug targets. J. Biol. Chem. 281, 17001-17010. doi: 10.1074/jbc.M512601200

Sharma, B., and Singh, S., and Siddiqi, N. J. (2014). Biomedical implications of heavy metals induced imbalances in redox systems. Biomed. Res. Int. 2014:640754. doi: 10.1155/2014/640754

Sharma, D., Kaur, G. S., and Khera, K. S. (2015). Triazophos-induced oxidative stress and histomorphological changes in ovary of female Wistar rats. Pestic. Biochem. Physiol. 117, 9-18. doi: 10.1016/j.pestbp.2014.09.004

Simurda, M. C., Keulen, H., Rekosh, D. M., and LoVerde, P. T. (1988). Schistosoma mansoni: identification and analysis of an mRNA and a gene encoding superoxide dismutase $(\mathrm{Cu} / \mathrm{Zn})$. Exp. Parasitol. 67, 73-84. doi: 10.1016/0014-4894(88)90010-0

Staal, Y. C., Hebels, D. G., Van Herwijnen, M. H., Gottschalk, R. W., Van Schooten, F. J., and Van Delft, J. H. (2007). Binary PAH mixtures cause additive or antagonistic effects on gene expression but synergistic effects on DNA adduct formation. Carcinogenesis 28, 2632-2640. doi: 10.1093/carcin/ bgm 182

Staal, Y. C., Pushparajah, D. S., Van Herwijnen, M. H., Gottschalk, R. W., Maas, L. M., Ioannides, C., et al. (2008). Interactions between polycyclic aromatic hydrocarbons in binary mixtures: effects on gene expression and DNA adduct formation in precision-cut rat liver slices. Mutagenesis 23, 491-499. doi: 10.1093/mutage/gen041

Struger, J., Grabuski, J., Cagampan, S., Sverko, E., and Marvin, C. (2016). Occurrence and distribution of carbamate pesticides and metalaxyl in southern ontario surface waters 2007-2010. Bull. Environ. Contam. Toxicol. 96, 423-431. doi: 10.1007/s00128-015-1719-x

Taghipour, H., Amjad, Z., Jafarabadi, M. A., Gholampour, A., and Norouz, P. (2014). Determining heavy metals in spent compact fluorescent lamps (CFLs) and their waste management challenges: some strategies for improving current conditions. Waste Manag. 34, 1251-1256. doi: 10.1016/j.wasman.2014.03.010 
Trost, B. M., and Tracy, J. S. (2017). Carbon-Nitrogen bond formation via the vanadium oxo catalyzed sigma tropic functionalization of allenols. Org. Lett. 19, 2630-2633. doi: 10.1021/acs.orglett.7b00961

Valko, M., Morris, H., and Cronin, M. T. D. (2005). Metals, toxicity and oxidative stress. Curr. Med. Chem. 12, 1161-1208. doi: 10.2174/0929867053764635

Wandiga, S. O. (2001). Use and distribution of organochlorine pesticides. The future in Africa. Pure Appl. Chem. 73, 1147-1155. doi: $10.1351 /$ pac200173071147

Wildemann, T. M., Weber, L. P., and Siciliano, S. D. (2015). Combined exposure to lead, inorganic mercury and methylmercury shows deviation from additivity for cardiovascular toxicity in rats. Appl. Toxicol. 35, 918-926. doi: 10.1002/jat.3092

Williams, D. L., Pierce, R. J., Cookson, E., and Capron, A. (1992). Molecular cloning and sequencing of glutathione peroxidase from Schistosoma mansoni. Mol. Biochem. Parasitol. 52, 127-130. doi: 10.1016/0166-6851(92)90042-I

Wiltrout, R. W., Ercegovich, C. D., Ceglowski, W. S. (1978). Humoral immunity in mice following oral administration of selected pesticides. Bull. Environ. Contam. Toxicol. 20, 423-431. doi: 10.1007/BF01683542

Xu, M. Y.,Wang, P., Sun, Y. J., and Wu, Y. J. (2017a). Metabolomic analysis for combined hepatotoxicity of chlorpyrifos and cadmium in rats. Toxicology 384, 50-58. doi: 10.1016/j.tox.2017.04.008
Xu, M. Y.,Wang, P., Sun, Y. J., Yang, L., and Wu, Y. J. (2017b). Jo nt toxicity of chlorpyrifos and cadmium on the oxidative stress and mitochondrial damage in neuronal cells. Food Chem. Toxicol. 103, 246-252. doi: 10.1016/j.fct.2017.03.013

Yan, F., Yang, W. K., Li, X. Y., Lin, T. T., and Lun, Y. N. (2008). A trifunctional enzyme with glutathione S-transferase, glutathione peroxidase and superoxide dismutase activity. Biochim. Biophys. Acta 1780, 869-872. doi: 10.1016/j.bbagen.2008.03.003

Zukowska, J., and Biziuk, M. (2008). Methodological evaluation of method for dietary heavy metal intake. J. Food Sci. 73, R21-R29. doi: 10.1111/j.1750-3841.2007.00648.x

Conflict of Interest Statement: The authors declare that the research was conducted in the absence of any commercial or financial relationships that could be construed as a potential conflict of interest.

Copyright (c) 2017 Singh, Gupta, Kumar and Sharma. This is an open-access article distributed under the terms of the Creative Commons Attribution License (CC BY). The use, distribution or reproduction in other forums is permitted, provided the original author(s) or licensor are credited and that the original publication in this journal is cited, in accordance with accepted academic practice. No use, distribution or reproduction is permitted which does not comply with these terms. 